\title{
How expectations affect reference point formation: an experimental investigation
}

\author{
Andreas Hack • Frauke von Bieberstein
}

Received: 14 December 2012/Accepted: 3 March 2014/Published online: 20 March 2014

(C) Springer-Verlag Berlin Heidelberg 2014

\begin{abstract}
This paper addresses two major topics concerning the role of expectations in the formation of reference points. First, we show that when expectations are present, they have a significant impact on reference point formation. Second, we find that decision-makers employ expected values when forming reference points (integrated mechanism) as opposed to single possible outcomes (segregated mechanism). Despite the importance of reference points in prospect theory, to date, there is no standard method of examining these. We develop a new experimental design that employs an indirect approach and extends an existing direct approach. Our findings are consistent across the two approaches.
\end{abstract}

Keywords Prospect theory $\cdot$ Reference dependent preferences $\cdot$ Reference point formation $\cdot$ Expectations

JEL Classification D81 $\cdot$ D84

\section{Introduction}

There is now much evidence that reference points play an important role in people's evaluations of outcomes of choice. According to Kahneman and Tversky's (1979) prospect theory, whether an outcome is perceived as a gain or a loss relative to a reference point strongly influences attitudes toward risk. In general, people exhibit risk aversion in the domain of gains, risk-seeking behavior in the domain of losses, and significantly greater aversion to losses than the appreciation of gains.

A. Hack $(\bowtie) \cdot$ F. von Bieberstein

Institute for Organization and Human Resource Management, University of Bern,

Engehaldenstrasse 4, 3012 Bern, Switzerland

e-mail: andreas.hack@iop.unibe.ch 
Therefore, the question of what constitutes a reference point is of great importance in the application of prospect theory. De Meza and Webb (2007), for example, observe that "Determining the reference income is the most problematic aspect of prospect theory" (p. 71). Kahneman and Tversky (1979) and Tversky and Kahneman (1992) suggest that various factors, such as the status quo, expectations or one's aspiration level, may determine the reference point. However, they do not specify how reference points are formed and updated, given these factors.

The present study focuses on the role of expectations in the formation of reference points. Expectations have long been believed to play a role in reference point formation, with several studies pointing in this direction (see the literature review below). However, clear-cut evidence about whether and how expectations affect reference point formation is still lacking. One reason for this absence of evidence is that reference points are not directly observable and thus difficult to study. To date, there is no standard approach to examining reference points; instead, two basic approaches have been adopted in the literature: indirect and direct approaches.

The indirect approach assumes that an individual has preferences in accordance with the value function of prospect theory. Given this assumption, the individual's risky choices enable us to infer the individual's reference point. For example, someone who behaves in a risk-seeking manner is likely to be in the loss domain relative to her reference point. The indirect approach thus assumes a stronger risk appetite below than above the reference point.

The direct approach asks participants to rate their satisfaction with a given outcome, providing a direct estimate of an individual's utility, given the outcome. The approach makes no assumption regarding the specific shape of the utility function but assumes that the shape remains unchanged when reference points shift during questioning. In addition, participants must be able to assess their satisfaction, which, in part, requires hypothetical scenarios with future outcomes.

As the two approaches make different assumptions, we employ both approaches in examining the role of expectations. First, we develop a new and easily implementable indirect approach to assess the role of expectations in reference point formation. Second, we extend the direct approach taken by Arkes et al. (2008) to include differences in expectations.

We employ both approaches to examine not only whether but how expectations affect reference point formation. Given multiple referents, Kahneman (1992) observes that a decision-maker could employ a single reference point (integrated mechanism) or several reference points (segregated mechanism) when evaluating an outcome. The frontiers between integrated and segregated models remain to be explored (Baucells et al. 2011).

Because we are interested in expectations, the expected value of an outcome is an easily available integrated mechanism that could be used as a single reference point. In contrast, with a segregated mechanism, each available outcome of a lottery could be used as one of several reference points. We thus examine whether the expected value of a lottery influences the reference point or whether any of the different available outcomes is more important in reference point formation. 
This study makes several contributions to the literature. First, we develop a new indirect approach and extend an existing direct approach to assess the influence of expectations on reference point formation. Second, we find that expectations do indeed play a role in the formation of reference points. Third, we find that in our setting, participants employ an integrated mechanism based on expected values in the combination process. Finally, all of our findings are consistent across both approaches. Therefore, based on our findings, both approaches are well-adapted to the examination of reference points. Other researchers may therefore utilize whichever of these approaches is best adapted to their specific research questions.

\section{Previous findings on expectations and reference point formation}

\subsection{Indirect approach}

The indirect approach assumes that an individual has preferences in accordance with the value function of prospect theory. Given this assumption, an individual's reference point can be inferred from the individual's choices. In a recent model, Schmidt and Zank (2012) follow this approach, providing a testable axiomatization of the existence and location of reference points.

Several empirical papers on risky choice employ a design similar to our indirect approach. However, such papers do not focus on the role of expectations. Koop and Johnson (2010) present evidence for the Tri-Reference-Point theory, showing that individuals simultaneously utilize a minimum requirement, the status quo, and a goal in risky decision tasks. Gneezy (2005), inferring reference point adaptation from people's decisions regarding when to sell stocks, finds an important role for historical peaks. A study closely related to our indirect approach but not focused on expectations is that of Kameda and Davis (1990). Examining the impact of prior monetary losses on risky decisions, these authors find that such losses increase risky behavior. Because they examine prior losses, their findings can be explained if reference points are given by the existing status quo (participants are in a loss situation relative to the status quo). Thus, expectations need not play a role in producing observed changes in risk-taking behavior. To analyze the impact of expectations, one would need to consider the impact of prior monetary gains that are smaller than expected. In this case, expectations, and not merely the existing status quo, could explain an increase in risky behavior.

In addition, some studies examine non-risky choices. Abeler et al. (2011) employ a real effort experiment, showing that expectations play a role in reference point formation. They examine the effect of an expectations-based reference point on the provision of effort, whereas we consider the effect of an expectations-based reference point on risk-taking behavior.

A different set of questions is examined in the marketing literature on reference prices (see Mazumdar et al. 2005 for an overview). Here, brand choice is predicted based on the difference between a reference price and the current purchase price. Winer (1986) finds empirical support for a model in which the reference price is formed by rational expectations, given past prices. This literature typically employs 
panel purchase data that are potentially subject to considerable noise. In addition to the marketing literature, reference points play an important role in the human resource management literature. For instance, Bartol and Martin (1998) show that expectations have quantifiable behavioral consequences. Based on their analysis of 152 part-time workers, they find that gaps between expected and actual wages predict subsequent turnover.

Most closely related to our indirect approach is the study of Post et al. (2008). Using data from the game show "Deal or No Deal", these authors find that risk aversion decreases after earlier expectations have been shattered by unfavorable outcomes; behavior that can be explained if former expectations influence the reference point. While the study of Post et al. (2008) offers the advantage of very high stakes, the dynamic game show setting is quite complicated, and there may be several uncontrollable side effects. We therefore believe that it is worthwhile to take the simplified approach of laboratory experiments.

\subsection{Direct approach}

Under the direct approach, participants are asked to rate their pleasure with a given outcome. Several authors have examined the effect of expected outcomes on satisfaction with actual outcomes, finding changes in reference points due to expectations. Mellers et al. $(1997,1999)$ show that unattained outcomes in a lottery affect self-reported emotions. Medvec et al. (1995) obtain similar findings with respect to satisfaction among Olympic medalists, while Heyman et al. (2004) find similar results for self-rated pleasure in sequences of lotteries. In a similar setting, Breiter et al. (2001) obtain neuroscientific support for the hypothesis that expectations-based counterfactuals affect reactions to outcomes. Although all these papers show the importance of expectations in reference point formation, none calculate the magnitude of reference point adaptation, nor do they examine the difference between segregation and the integration of expected information.

A different strand of the literature, beginning with Heath et al. (1999), considers goals as reference points. The authors show that goals affect participants' satisfaction in a manner consistent with the value function of Prospect Theory. Although one cannot equate goals with expectations (Klein 1991), anticipated goals affect expectations of future outcomes, indicating a role of expectations in reference point formation. The focus of this literature is on self-set goals in an environment in which a decision-maker has some control over the outcome. In contrast, we consider expectations in a setting in which the individual has no control over the outcome.

Recently, several authors have acknowledged the concept of variable and adaptive reference points, thus examining the formation of reference points over time. Lin et al. (2006) consider multiple reference points and show that counterfactuals and expected outcomes play an important role in investor regret. In their examination of the path dependency of preferences, Hoeffler et al. (2006) predict a key role for the historical status quo in shaping preferences. Studying happiness in the context of individual wealth changes, Chen and Rao (2002) find partial reference point adaptation to recent wealth levels. Baucells et al. (2011) implement a novel experiment pertaining to stock price information. They find that 
reference prices are determined as combinations of first and last prices, with intermediate prices receiving smaller and non-decaying weights. However, their model does not consider expectations.

Our direct approach is most closely related to Arkes et al. (2008), who develop a new method to examine the magnitude of shifts in reference points following gains and losses. Focusing on differences between the historical and recent status quo, they find that reference point adaptation is significantly greater following a gain than a loss. In their Experiment 5, Arkes et al. (2008) fix the expectations of their participants in order to reduce the potential impact of such expectations on reference point formation. Thus, they do not consider differences in expectations and their resulting influence on reference point adaptation.

\section{Previous findings on multiple referents and reference point formation}

Aside from the question of the importance of expectations in the reference point formation process, one might also wonder how these expectations are formed and, in particular, what determines experienced utility if multiple potential outcomes are given. This question can be attributed to Kahneman's (1992) discussion of the psychology of mixed feelings. In his example, an employee is given good reason to expect a $\$ 5,000$ raise but ultimately receives only $\$ 3,000$. Kahneman (1992) discusses two possible mechanisms of reference point formation: a single reference point that is a weighted composite of zero and the $\$ 5,000$ raise (integrated mechanism) and one or the other of the two possible reference points (segregated mechanism).

Although there is ample evidence that people indeed employ multiple referents (e.g., Sullivan and Kida 1995; Bell and Lattin 2000; Short and Palmer 2003), there is little empirical evidence regarding the underlying mechanism of comparison [i.e., whether an outcome is compared to a single reference point that is a combination of various referents (integrated mechanism) or is compared with each reference point separately (segregated mechanism)]. Whereas early studies on adaptation level theory (Helson 1964) and brand choice (Winer 1986) assert that people aggregate multiple reference points through a weighted averaging process, Ordonez et al. (2000) find evidence of the use of a segregated mechanism when people assess salary satisfaction and payment fairness.

The contrasting results could be caused by norms, that is, "ad hoc representations which reflect the momentary activation of instances retrieved from memory or constructed in imagination" (Kahneman 1992, pp. 306-307). In practice, the process of combining multiple reference points might be influenced by the salience, recency, or comparability of various referents. Ordonez et al. (2000) argue, for example, that reference points are more likely to be integrated when the referents are easily comparable. Baucells et al. (2011) find that the most recent reference point receives a larger weight in the combination process than prior reference points.

Another important factor influencing the combination process is the context in which information is presented, where the absolute values of the present situation are ignored (Kahneman 1992). This could be due to the frequency principle, that is, that possible reference points are not combined, but rather one single reference point 
is selected due to its relative frequency (Diener et al. 1990). The frequency model is tested by Highhouse et al. (2003) in the case of salary expectations.

While the above findings mainly concern the mental combination of existing outcomes, to the best of our knowledge, very little research has been done on the combination process used to form reference point relevant expectations when confronted with multiple possible future outcomes. As Ordonez et al. (2000) notes, "an important challenge for future theoretical and empirical work is to understand when multiple reference points are processed individually and when alternative processing rules are evoked". Our work attempts to shed light on this open research question.

The remainder of this article is organized as follows. In Sect. 4, we show the potential impact of expectations, given prospect theory preferences. In Sect. 5, we present the experimental study, and in Sect. 6, we present the questionnaire study. Section 7 concludes.

\section{The potential impact of expectations, given prospect theory preferences}

Before presenting our experimental design in greater detail, we illustrate how reference points can be affected by expectations and how such adaptation can affect subsequent risky choices. We define expectations as recently formed expectations regarding prospective outcomes in the subsequent time period. Consider the following situation: At some initial date $t=0$, the initial reference point $R_{0}$ is formed. This could be, for example, the purchase price of a stock (historical status quo). This reference point determines the root of the prospect theory value function (see the solid line in Fig. 1).

Outcomes above the reference point are coded as gains, and outcomes below the reference point are coded as losses.

At $t=1$, the individual receives some new information regarding the actual status quo, denoted as $P_{1}$, e.g., the current stock price. Research by Arkes et al. (2008) and Baucells et al. (2011) has shown that the reference point will partially adapt to this new information, resulting in a new reference point $R_{1}$, which is a function of $P_{1}$ [formally, $R_{1}\left(P_{1}\right)$ ].

How can expectations affect this adaptation? Consider again the situation at $t=1$. At this point, the individual not only learns the recent status quo but forms expectations $E_{1}$ regarding the possible outcome at $t=2$. ${ }^{1}$ Consider the case where the individual can form low expectations $E_{1}^{L}$ or high expectations $E_{1}^{H}$, where $E_{1}^{L}<E_{1}^{H}$. If expectations play a role in reference point formation, the reference

\footnotetext{
1 We follow Köszegi and Rabin $(2006,2007)$ and consider those expectations held in the "recent" past $(\mathrm{t}=1)$ about current outcomes $(\mathrm{t}=2)$. As they point out, this should not mean that beliefs are slow to adjust to new information but that preferences do not instantaneously change when beliefs do. They give the following example for this setting: "When somebody finds out $5 \mathrm{~min}$ ahead of time that she will for sure not receive a long-expected $\$ 100$, she would presumably immediately adjust her expectations to the new situation, but she will still 5 min later assess not getting the money as a loss" (Köszegi and Rabin 2006, footnote 9).
} 


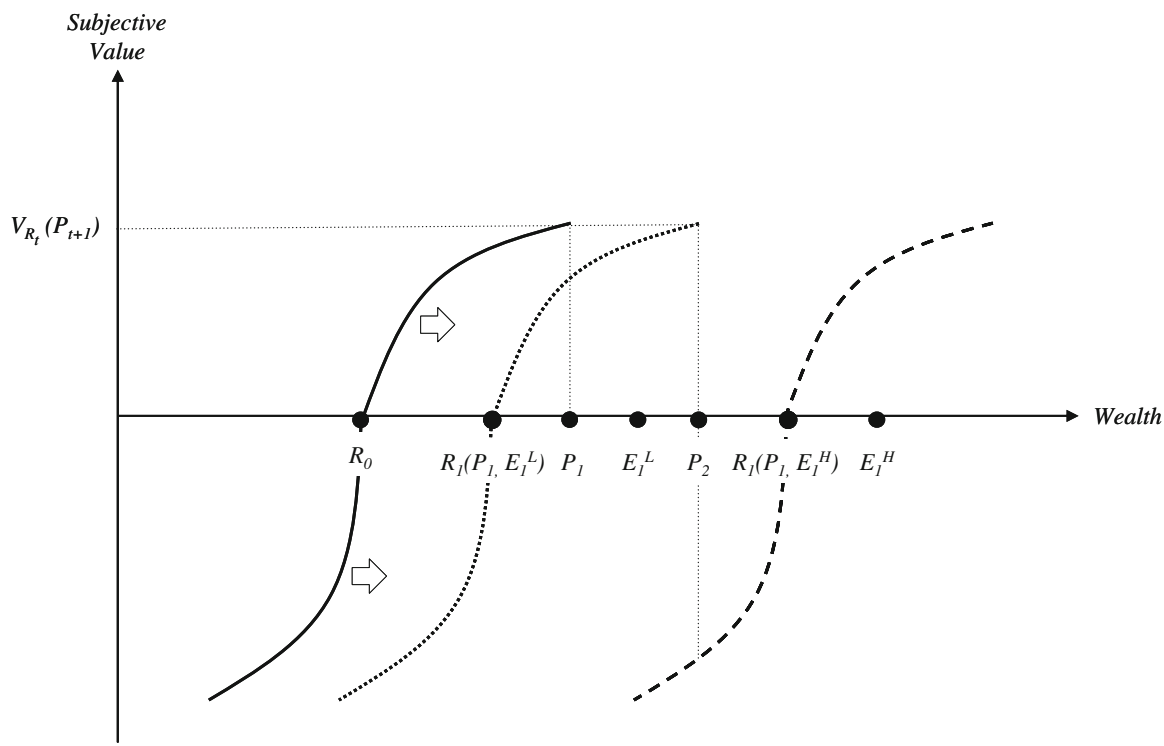

Fig. 1 The potential role of expectations

point should be lower for low expectations compared with high expectations. Formally, $R_{1}\left(P_{1}, E_{1}^{L}\right)<R_{1}\left(P_{1}, E_{1}^{H}\right)$ for any given value $P_{1}$.

This situation is depicted in Fig. 1. If the reference point changes, the value function moves along the $\mathrm{x}$-axis, so that the root is once again determined by the new reference point. In Fig. 1, we assume that the shape of the value function remains unchanged during this adaptation. The root of the dotted line represents the new reference point $R_{1}\left(P_{1}, E_{1}^{L}\right)$, given low expectations, and the root of the dashed line shows the corresponding reference point $R_{1}\left(P_{1}, E_{1}^{H}\right)$, given high expectations. With respect to the initial $R_{0}$, we thus observe a higher adaptation at $\mathrm{t}=1$ for high expectations compared with low expectations.

Therefore, the actual outcome at $t=2$, denoted $\mathrm{P}_{2}$, will be evaluated differently, depending on prior expectations. For example, if $\mathrm{P}_{2}$ lies above the reference point $R_{1}\left(P_{1}, E_{1}^{L}\right)$, the outcome will be assessed as a gain. Given prospect theory preferences, a person in this situation will generally exhibit risk-averse behavior at $t=2$. In contrast, if $\mathrm{P}_{2}$ lies below the reference point $R_{1}\left(P_{1}, E_{1}^{H}\right)$, the outcome will be assessed as a loss. Given prospect theory preferences, a person in this situation will generally exhibit risk-seeking behavior.

\section{Experimental study: the indirect approach}

The following experiment was designed to (a) test the impact of past expectations on reference point adaptation and (b) shed light on reference point formation, given past expectations, i.e., whether individuals base their expectations on expected values (integration) or on single possible outcomes (segregation). 


\subsection{Participants}

In total, 121 business undergraduates at the University of Bern, Switzerland, participated in the experiment. The mean age was 21 years, and $42 \%$ of the participants were women. Participants were paid according to their gains in the lotteries. Payments ranged from $4 \mathrm{CHF}$ to $22 \mathrm{CHF}$, with an average payment of 10.9 $\mathrm{CHF}$. The experiment and the subsequent questionnaire required approximately 25 min to complete.

\subsection{Design, procedure and materials}

The experiment included three between-subjects treatments: a control treatment and two experimental treatments.

In the first part of the experiment, participants in the control treatment $(n=29)$ received a fixed initial endowment of $4 \mathrm{CHF}$, whereas participants in the two experimental treatments were presented with a lottery. Participants in treatment 1 $(n=53)$ could win an initial endowment of 4 CHF with $50 \%$ probability or an initial endowment of $8 \mathrm{CHF}$ with $50 \%$ probability. Thus, participants were confronted with an expected endowment of 6 CHF. Participants were evenly divided into two groups, and a flip of a coin decided which group was awarded $4 \mathrm{CHF}$ and which group was awarded $8 \mathrm{CHF}$.

Participants in treatment $2(\mathrm{n}=39)$ could win an initial endowment of $4 \mathrm{CHF}$ with $75 \%$ probability or an initial endowment of $12 \mathrm{CHF}$ with $25 \%$ probability. Thus, the expected endowment was $6 \mathrm{CHF}$, which is equal to the expected endowment in treatment 1 . The lottery was conducted by evenly dividing participants into four groups. The initial endowment for each group was allocated by drawing lots. Ultimately, three groups were awarded $4 \mathrm{CHF}$, and one group was awarded 12 CHF.

We were mainly interested in the participants who were endowed with $4 \mathrm{CHF}$, either through the lotteries or through the fixed initial endowment. Thus, all participants were confronted with the same recent status quo (4 CHF), and both experimental groups had the same expected endowment (6 CHF). The highest value was higher in treatment 2 than in treatment 1 (12 CHF compared with $8 \mathrm{CHF}$ ), whereas the highest probability placed greater weight on the low value $(75 \%$ probability of $4 \mathrm{CHF})$ in treatment 2 than in treatment $1(50 \%$ probability of 4 CHF).

In the second part of the experiment, we examined participants' willingness to take risks. Following the approach of Holt and Laury (2002), we presented all participants with a choice table between a paid lottery and different safe payments (see the table in "Appendix 1"). The written instructions explained the choices available to the participants in the table and how payments would be allocated. We also provided a short verbal explanation. Participants made choices in a table with 17 rows. In each row, they were presented with a choice of whether to play a lottery or opt for a safe payment. In the lottery, they would either win $10 \mathrm{CHF}$ with $50 \%$ probability or win nothing, also with $50 \%$ probability. Each row contained exactly the same lottery, but the safe option gradually increased in $0.5 \mathrm{CHF}$ increments from 
an initial $0 \mathrm{CHF}$ in row one to $8 \mathrm{CHF}$ in row seventeen. The number of safe payments a participant chose provides information about his or her willingness to take risks. The higher the number of safe payment choices, the more risk-averse the participant is.

After all choices had been made, one row was randomly selected. The choice in this row was payoff-relevant: either the participant was awarded with the safe payment, or a flip of a coin determined whether the participant won the $10 \mathrm{CHF}$ or won nothing. This procedure gave participants an incentive to make the choice in each row according to their true preferences and thus was incentive-compatible.

Finally, after the experiment, all participants answered a brief paper-based questionnaire containing questions on gender, age and individual risk propensity.

\subsection{Predictions}

The first aim of the experiment was to determine the impact of past expectations on reference point adaptation. Given diminishing sensitivity and the assumption that the adaptation of a reference point is influenced by past expectations, participants in treatments 1 and 2 who had received $4 \mathrm{CHF}$ in the lottery should be more willing to take risks.

For ease of exposition, let Prediction 1 be the proposition that participants employ the expected value (integrated mechanism) when forming an expectationsbased reference point. The reasoning is the same for a segregated mechanism. The argument can be shown in Fig. 1: at $\mathrm{t}=0$, all participants face a historical reference point $R_{0}$. At $\mathrm{t}=1$, participants in the experimental treatments are given the option to play a lottery with an expected value of $6 \mathrm{CHF}\left(E_{1}^{H}\right)$, whereas participants in the control treatment are informed that they will receive a fixed endowment of $4 \mathrm{CHF}$ $\left(E_{1}^{L}\right)$. As a result, participants in the control treatment adapt their reference point toward $E_{1}^{L}(4 \mathrm{CHF})$, resulting in a new reference point $R_{1}\left(E_{1}^{L}\right)$ (see the dotted line in Fig. 1). ${ }^{2}$ In contrast, the expected value of the lottery $\left(E_{1}^{H}=6 \mathrm{CHF}\right)$ is higher, and if past expectations influence reference point formation, participants in the experimental treatments are likely to adapt their reference points more strongly, resulting in the new reference point $R_{1}\left(E_{1}^{H}\right)$ (see the dashed line in Fig. 1). Therefore, at $\mathrm{t}=2$, after the first part of the experiment and after receiving the lower outcome $P_{2}$ (4 CHF), participants in the experimental treatments will view the money as a loss, given their reference point $R_{1}\left(E_{1}^{H}\right)$. In contrast, participants in the control treatment will consider themselves to be in the gain region relative to their reference point $R_{1}\left(E_{1}^{L}\right)$.

We make the important assumption that the reference point does not again change at this point but remains at its present level during the choice part of the experiment. Thus, experimental group participants should choose the lottery over the safe payment more frequently than participants in the control treatment, although both have received the same amount of money. If so, expectations clearly

\footnotetext{
${ }^{2}$ Note that in contrast to Fig. 1, there is no actual outcome P1 in $\mathrm{t}=1$ when the lotteries are announced. This intermediate outcome P1 will become meaningful in Experiment 2.
} 
influence the formation and adaptation of reference points. If not, expectations appear to be irrelevant to the formation of reference points.

Prediction 1 Participants in the control treatment choose safe payments more frequently than participants in the experimental treatments.

To avoid complexity, we have based the preceding argument regarding expectations $E_{1}^{H}$ on expected values. However, the second aim of the experiment is to shed light on the formation of expectations in the process of reference point adaptation, i.e., on whether individuals anchor on expected values (integration) or place specific weights on single possible outcomes (segregation). If participants' reference points are influenced by expected values, there should be no difference in the risk taking behavior of the two experimental treatment groups. This is because participants in both treatments are confronted with the same expected value of 6 CHF ( $E_{1}^{H}$ are identical, and thus $R_{1}\left(E_{1}^{H}\right)$ are also identical). In contrast, if participants' reference points are more strongly influenced by one individual possible outcome (segregation), there should be differences in the number of safe payment choices. The number of safe payment choices in treatment 1 may be higher than that in treatment 2, i.e., participants may be more risk-averse in treatment 1. This is the case if the reference point is lower in treatment 1 than in treatment 2 and would suggest the relative importance of the lower but more probable (75 vs $50 \%$ ) outcome of the lottery. Alternatively, if the number of safe payment choices is lower in treatment 1 , this would suggest the importance of the higher possible outcome (12 $\mathrm{CHF}$ vs $8 \mathrm{CHF}$ ), irrespective of its probability. Regardless of which treatment induces more safe payment choices, both results would imply that integration is not the major mechanism leading to relevant expectations in the process of reference point formation.

Due to our experimental setting, we expect that the process of reference point formation follows an integrated mechanism. Both reference points are easily comparable, and the expected value can easily be calculated in all treatments, suggesting use of an integrated mechanism (Ordonez et al. 2000). Furthermore, neither salience nor recency should affect the results, nor do we expect any interference due to frequency effects, as the lottery is played only once. We thus hypothesize the following:

Prediction 2 There is no difference in the number of safe payment choices between participants in treatment 1 and treatment 2 .

\subsection{Alternative predictions}

In the above reasoning regarding both predictions, we use risk preferences based on diminishing sensitivity to infer the reference point. Given prospect theory preferences, one could also infer the reference point from loss aversion or from probability weighting. Both of these approaches have been used in the literature (for a discussion, see Schmidt and Zank 2012). In the following, we discuss the application of both alternatives in our setting. 
Loss aversion is variously defined in the literature (for an overview, see Abdellaoui et al. 2007). All such definitions have in common the notion that individuals are more sensitive to losses than to commensurate gains. Individuals thus seek to avoid losses if the opportunity costs of doing so are not too high. In our setting, this means that decisions in the second part of the experiment could be driven by a desire to offset potential losses incurred in the first part. Thaler and Johnson (1990) present evidence of such a break-even effect after participants have realized real monetary losses (compared to a status quo). For the control treatment, we expect participants to be in the gain region after the first part. Loss aversion thus cannot predict choice behavior in the second part. For treatments 1 and 2, individuals with a reference point of $6 \mathrm{CHF}$ and who just received $4 \mathrm{CHF}$ could try to offset this loss of $2 \mathrm{CHF}$. They would thus choose the lottery in the first 4 choices and switch to the safe payment subsequently (2 CHF or more for sure). In contrast, individuals with a reference point of 8 (12) CHF and who received 4 CHF could try to offset this loss of 4 (8) CHF. They would choose the lottery in the first 8 (16) choices and then switch to safe payment. Taken together, these results would entail that loss aversion cannot predict differences between the control treatment and the experimental treatments. Comparing the experimental treatments, loss aversion would predict no difference between both treatments if the reference point is given by the expected value. Loss aversion and diminishing sensitivity thus both arrive at Prediction 2. Similarly, as also discussed with respect to diminishing sensitivity, more safe payment choices in treatment 1 compared to treatment 2 would indicate a lower reference point in treatment 1 . The predictions based on loss aversion are thus consistent with the predictions based on risk preferences originating from diminishing sensitivity.

In addition to diminishing sensitivity and loss aversion, the reference point could also be inferred from probability weighting. In particular, it has been shown that the probability weighting function for losses is more "elevated" than that for gains (Abdellaoui 2000; Fehr-Duda et al. 2006). In our setting, the reference point formed in the first part of the experiment could influence perceived probabilities in the second part. The weighting functions proposed in the literature usually assume no differences in weighting for events that are certain. A safe payment should thus be evaluated as certain, irrespective of the reference point. In contrast, a lottery that offers the chance to win $10 \mathrm{CHF}$ with $50 \%$ probability or nothing with $50 \%$ probability could be perceived differently for people in gain and loss domains.

In the control treatment, we expect participants to be in the gain region after the first part of the experiment. In contrast, individuals in treatments 1 and 2 may view themselves as being in a loss region relative to their reference point. Consequently, these individuals would perceive the lottery as a mixed gamble, remaining in the loss situation after winning nothing or ending up with a gain after winning $10 \mathrm{CHF}$. Probability weighting of gains and losses puts more weight on the probability of losses and thus renders the lottery less attractive. Based on probability weighting, we would thus predict fewer lottery choices in the experimental treatments compared with the control treatment if the reference point is influenced by expectations. Taken together, arguments based on diminishing sensitivity and on probability weighting both predict no difference between choices in the control 
treatment and in the experimental treatments if expectations do not influence the reference point. If expectations influence the reference point, diminishing sensitivity predicts more safe payment choices, and probability weighting predicts fewer safe payment choices, in the control treatment compared with the experimental treatments. Ultimately, which of these two effects predominates (if any) is an empirical question.

\subsection{Results}

Our main interest is in participants endowed with $4 \mathrm{CHF}$, either through the lotteries or through the fixed initial endowment. These participants were confronted with the same recent status quo (4 CHF) and, in the case of participants in the experimental treatments, the same expected value (6 CHF).

We begin our empirical analysis by presenting the descriptive results of safe payment choices in the risk task for those participants who received $4 \mathrm{CHF}$ during the first part of the experiment. As seen in Table 1, the median number of safe payment choices in all treatments was 7 , indicating risk-neutral behavior. However, participants in the control treatment chose safe payments on average 7.76 times, participants in treatment 1 chose safe payments on average 6.89 times, and participants in treatment 2 chose safe payments on average 6.52 times. Thus, participants in both experimental treatments show, on average, a relatively higher propensity to take risks than those in the control treatment. Additionally, we calculated the number of safe payment choices for all groups by applying the 75 th percentile as a measure of the switching point for the vast majority of participants in each group. Descriptive results support the results indicated by the average calculations: The number of safe payments for the 75 th percentile in the control treatment was 9 , while the number of safe payment choices for the 75 th percentile in both experimental treatments was 8 .

To assess the statistical significance of these results, we tested the data using the non-parametric one-tailed Mann-Whitney-U-test and the corresponding parametric $t$ test (see Table 1 for results). The results corroborate the hypothesis that participants in both experimental treatments show a higher propensity to take risks compared with participants in the control treatment. The differences in the number of safe payment choices between control treatment participants and treatment 2 participants are even more pronounced than those between the control treatment participants and treatment 1 participants. Our results therefore support prediction 1 , that expectations play a crucial role in the process of reference point adaptation.

To distinguish between the multiple potential determinants of reference points, given expectations, we analyze differences in the number of safe payment choices between the two experimental groups. To summarize, no differences in risk-taking behavior would indicate that the expected value (integration) is used to form the reference point, whereas differences would indicate that more weight is added either to the highest possible outcome or to the most probable outcome of the lottery (segregation) in forming the reference point. With an average of 6.89 safe payment choices in treatment 1 and 6.52 in treatment 2, we find slightly greater risk-seeking behavior in participants confronted with a high possible outcome of $12 \mathrm{CHF}$ in the 
Table 1 Test on differences between control and experimental treatments (4 CHF)

\begin{tabular}{|c|c|c|c|c|c|}
\hline $\begin{array}{l}\text { Number of safe } \\
\text { payment choices }\end{array}$ & $\begin{array}{l}\text { Treatment } 1 \\
\text { (4 CHF) }\end{array}$ & & $\begin{array}{l}\text { Control treatment } \\
\text { (4 CHF) }\end{array}$ & & $\begin{array}{l}\text { Treatment } 2 \\
(4 \mathrm{CHF})\end{array}$ \\
\hline Median & 7 & & 7 & & 7 \\
\hline Mean & 6.89 & & 7.76 & & 6.52 \\
\hline 75-percentile & 8 & & 9 & & 8 \\
\hline Standard deviation & 2.097 & & 2.294 & & 2.385 \\
\hline Mann-Whitney-U $(p)$ & & $300.50(.040)$ & & $272.00(.009)$ & \\
\hline $\mathrm{t}(p)$ & & $1.486(.070)$ & & $2.020(.024)$ & \\
\hline
\end{tabular}

first lottery. However, statistical comparison shows no significant differences in risk-taking behavior $(\mathrm{U}=347.5 ; p=.338 ; \mathrm{t}=0.631 ; p=.265)$. Our findings are a sign of an integrative approach to reference point formation when expectations are salient and easily comparable, corroborating prediction 2 .

In the interest of completeness, we additionally report on differences between participants in the control treatment and the experimental treatments, where participants are endowed with $8 \mathrm{CHF}$ and $12 \mathrm{CHF}$, respectively. Participants in treatment $1(8 \mathrm{CHF})$ chose safe payments on average 7.12 times, while participants in treatment $2(12 \mathrm{CHF})$ chose safe payments on average 7.00 times, compared with an average of 7.76 safe payment choices for participants in the control treatment. Statistical comparison, using the Kruskal-Wallis-H-Test, indicates no significant differences in risk-taking behavior between participants earning the highest available amounts of money in all three treatments (Chi Square $=3.619 ; d f=2$; $p=.164)^{3}$

Furthermore, to underscore the claim that there should be no inferences due to salience, we conducted an additional treatment, treatment 3, with 29 business undergraduates at the University of Bern, Switzerland. In this treatment, participants could win either $4 \mathrm{CHF}$ with $90 \%$ probability or $24 \mathrm{CHF}$ with $10 \%$ probability. The spread between the two possible payoffs is much larger than that between the payoffs in treatments 1 or 2 . If salience drives reference point formation, one would expect a significant difference in the risk taking behavior of participants in treatment 3 and participants in treatments 1 and 2 .

With an of average 6.62 safe payment choices (mean: 7 ; 75 th percentile: 8 ), participants in experimental treatment 3 on average exhibit a high propensity to take risks relative to those in the control treatment $(\mathrm{U}=285.00 ; p=.015 ; \mathrm{t}=1.785$; $p=.040$ ). More importantly, we could not find significant differences between treatment 3 and treatment $1(\mathrm{U}=361.00 ; p=.235 ; \mathrm{t}=0.440 ; p=.331)$ and

\footnotetext{
3 The higher willingness of those participants in the experimental treatments to take risks, even if not significant, could first be due to the "hot hand effect" (Rabin and Vayanos 2010; Croson and Sundali 2005). Participants in the experimental treatments won the higher amount of money during the first lottery and thus might believe in a run of good luck. Second, the higher willingness could be due to the more pronounced "house-money effect" (Thaler and Johnson 1990) as participants in the experimental treatments received a higher amount of money ( $8 \mathrm{CHF}$ or $12 \mathrm{CHF}$ ) compared with those in the control treatment $(4 \mathrm{CHF})$.
} 
between treatment 3 and treatment $2(\mathrm{U}=408.50 ; p=.425 ; \mathrm{t}=-0.159$; $p=.437)$. The results thus corroborate our claim that salience does not interfere with our finding that participants employ an integrated mechanism in reference point formation.

\subsection{Discussion}

Since the introduction of prospect theory, the notion that expectations may affect reference point formation has been widely discussed (Kahneman and Tversky 1979). However, showing such an influence empirically has proven to be difficult. Some empirical studies, employing an indirect method involving observations of real choices, find that expectations do indeed play a role in reference point formation (Winer 1986; Bartol and Martin 1998, Post et al. 2008). Such inferences from field data, however, are subject to considerable noise. We therefore employed an indirect approach in a controlled laboratory setting. Consistent with previous literature, we find that expectations impact subsequent risk-taking behavior, in line with the predictions of prospect theory. Our findings could therefore be considered a strong demonstration of the impact of expectations on reference point adaptation.

Our findings are even more robust, given the conflicting prediction with respect to risk-taking behavior derived from hot hand beliefs. The notion of a hot hand is often described as belief in positive serial autocorrelation in a non-autocorrelated series (Croson and Sundali 2005). Given such a belief, people are more likely to predict continuation of a good or a bad streak, even when facing random sequences (Gilovich et al. 1985; Croson and Sundali 2005). Hot hand beliefs, translated into our experiment, would imply that participants endowed with $4 \mathrm{CHF}$ during the lottery experienced bad luck and might therefore behave in a more risk-averse manner during the risk task. However, as our results continue to show higher riskseeking behavior of participants in the experimental treatments, the use of expectations in the process of reference point formation is even more likely.

The second aim of this set of experiments was to shed light on the question of whether participants use an integrative mechanism to form expectations relevant to reference point formation or anchor on single possible outcomes. Our experiment does not test the frequency model (Diener et al. 1990) but focuses on the fundamental question of whether expectations are formed using an integrative mechanism or a single salient point. Our results suggest an integrative mechanism. Neither the highest expected value nor the most probable expected value dominated in our one-shot-choice setting. This finding accords with the argument of Ordonez et al. (2000) that integration is more likely when referents are easily comparable, which is clearly the case in our setting.

It may be worth repeating the procedure in a sequential-choice setting. Due to frequency and learning effects, it might be possible for either the highest or lowest possible endowment to become dominant, irrespective of ex ante probabilities. ${ }^{4}$

\footnotetext{
${ }^{4}$ For the effects of learning in sequential-choice settings see March (1996) or Erev and Barron (2005).
} 
One could argue that the absence of differences in risk-taking behavior does not suggest an integrative mechanism but points to the predominance of the lower outcome level of the lottery in reference point formation without taking occurrence probabilities into account. This would imply that expectations do not play a role in the formation of reference points. As the comparison of risk-taking behavior of participants in the control treatment and experimental treatments show, however, expectations do affect choice behavior. Thus, it is not probable that the lower outcome level alone constitutes the reference point.

To summarize, our indirect approach shows that expectations most likely play a role in reference point formation and that expectation-based reference points are likely to be formed using an integrative mechanism.

\section{Questionnaire study: the direct approach}

The goal of the questionnaire study was to use a direct approach in examining the role of expectations in the formation of reference points and the comparison mechanism that participants employ. To do so, we utilized a method introduced by Arkes et al. (2008) and extended it to an examination of the effect of differences in expectations.

\subsection{Participants}

A total of 471 business undergraduates at a large German university, the Technische Universität Dortmund, answered our brief questionnaire in a classroom setting. The total number of respondents for each scenario is denoted by $n$. All students voluntarily completed the questionnaire. The mean age of the participants was 23 , and $41.2 \%$ of the participants were women. All participants took part in a lottery of 40 movie theatre tickets.

\subsection{Design, procedure and materials}

The study used a between-subjects design with seven treatments: one control treatment and six experimental treatments that varied with respect to information provided regarding expected price movements. The participants were randomly assigned to one treatment, given task instructions and asked to complete a paperbased questionnaire. Participants in the control treatment read the following scenario taken from Arkes et al. (2008) and translated into German:

"Two months ago, you bought a stock for $30 €$ per share. One month ago, you were delighted to learn the stock was trading higher-at $36 €$ per share. This month, you decide to check the stock's price again. At what price would the stock need to trade today to make you just as happy with the stock's price this month as you were when you learned the stock had risen from 30 to $36 €$ last month?"

As this basic scenario does not control for past expectations, we extended the approach to examine the role of prior expectations. In the experimental treatments, the following additional information was presented after the second sentence: "One 
month ago, you also learned that this month's stock price is expected to range between $x$ and $y €$, with each price within this interval being equally likely."

In the base treatment $\mathrm{A}$, the interval was set at 30-50€; in the low treatment $\mathrm{A}$, we lowered the expectations to range from 25 to $45 €$; and in the high treatment $\mathrm{A}$, we increased the expectations to range from 35 to $55 €$. For the remaining three treatments (treatments B), we extended the range of possible outcomes on both the lower and upper bounds by $10 €$, resulting in an interval ranging from 20 to $60 €$ for the base treatment $\mathrm{B}, 15-55 €$ for the low treatment $\mathrm{B}$ and $25-65 €$ for the high treatment B (Table 2).

After reading the scenario, participants were asked to indicate the stock price that would generate the same subjective value as the previous price increase. Furthermore, on a second sheet, they were asked to reveal their expectations regarding the actual stock price. Afterwards, participants completed a short paperbased questionnaire that was not part of this study.

\subsection{Predictions}

The stock price scenario allows us to calculate magnitudes of reference point adaptation under the assumptions that the purchase price serves as the initial reference point $\left(P_{0}=R_{0}=30 €\right)$ and that the shape of the value function is stable over time. The reasoning, which is based on Arkes et al. (2008), is illustrated in Fig. 1: At $\mathrm{t}=1$, the stock price has changed from $P_{0}=30 €$ to $P_{1}=36 €$. The individual evaluation of this change is based on the initial reference point $R_{0}$, resulting in the subjective value $V_{R_{0}}\left(P_{1}\right)$ at $\mathrm{t}=1$. In the experimental treatments, participants receive additional information regarding the range of stock prices expected at $\mathrm{t}=1$ for the next period $\left(E_{1}\right)$.

We asked participants what stock price $P_{2}$ at $\mathrm{t}=2$ would generate the same subjective value. Formally, we asked participants to specify a value of $P_{2}$, such that the following equality holds: $V_{R_{1}}\left(P_{2}\right)=V_{R_{0}}\left(P_{1}\right)$. If the shape of the value function remains unchanged, we know that the distance between the new reference point $R_{1}$ and $P_{2}$ remains constant, i.e., $P_{2}-R_{1}=P_{1}-R_{0}$. This allows us to deduce the new reference point $R_{1}$, which is the only unknown in the equation. Given $R_{1}$, we can calculate the magnitude of the reference point adaptation defined as $\Delta R=R_{1}-R_{0}$. The following equation, taken from Arkes et al. (2008), summarizes the relation:

$$
P_{2}-R_{1}=P_{1}-R_{0} \Rightarrow \Delta R=R_{1}-R_{0}=P_{2}-P_{1} .
$$

Prior research has shown that $R_{1}\left(P_{1}\right)$. In the present research, we seek to test the impact of expectations on reference point formation, i.e., $R_{1}\left(P_{1}, E_{1}\right)$. If expectations play a role, the magnitude of reference point adaptation should vary significantly both between the different treatments $\mathrm{A}$ and the different treatments $\mathrm{B}$. The reasoning can again be illustrated using Fig. 1. Compare, for example, base treatment A with high treatment A. Participants in both treatments revert to the same historical status quo $\left(R_{0}=30 €\right)$ and have the same information regarding the recent status quo $\left(P_{1}=36 €\right)$ but differ in their expectations and in their resulting expected values $\left(E_{1}\right)$. Participants in the base treatments are confronted with lower 
Table 2 Overview of treatments

\begin{tabular}{lllll}
\hline Treatment & Expectations & Range & $\begin{array}{l}\text { Resulting } \\
\text { expected } \\
\text { value }\end{array}$ & Description \\
\hline Control treatment & No explicit expectations & None given & None given & As Arkes et al. (2008) \\
Base treatment A & $30-50 €$ & $20 €$ & $40 €$ & Base expectations \\
Low treatment A & $25-45 €$ & $20 €$ & $35 €$ & Low expectations \\
High treatment A & $35-55 €$ & $20 €$ & $45 €$ & High expectations \\
Base treatment B & $20-60 €$ & $40 €$ & $40 €$ & Base expectations \\
Low treatment B & $15-55 €$ & $40 €$ & $35 €$ & Low expectations \\
High treatment B & $25-65 €$ & $40 €$ & $45 €$ & High expectations \\
\hline
\end{tabular}

expectations $\left(E_{1}^{L}: 40 €\right.$; range $\left.30-50 €\right)$ than participants in the high treatments $\left(E_{1}^{H}\right.$ : $45 €$; range $35-55 €)$. Therefore, it is expected that the resulting reference point $R_{1}\left(P_{1}, E_{1}^{H}\right)$ in the high treatment and thus the reference point adaptation $(\Delta R)$ will be higher. The same reasoning applies to all other comparisons between base, low and high treatments within a given group (A or B).

Prediction 3a The magnitudes of reference point adaptation by participants in the base treatments are larger than those of their counterparts in the corresponding low treatments.

Prediction 3b The magnitudes of reference point adaptation by participants in the base treatments are smaller than those of their counterparts in the corresponding high treatments.

Next, we derive predictions regarding the formation of expectations in the process of reference point adaptation. Given the results of the indirect approach, we expect no differences in the magnitudes of reference point adaptation between treatments with the same expected values. This is because, again, we expect that participants anchor their reference points on expected values and not on single possible outcomes. Compare, for example, participants in the base treatments A and B. Both groups are confronted with the same expected value of $40 €$ but different lower bounds (30 vs $20 €$ ) and upper bounds (50 vs $60 €)$ of their probability intervals. If participants anchor their expectations on one or the other extreme value, then there should be differences in the magnitudes of reference point adaptation. If the magnitude in base treatment $\mathrm{A}$ is higher than that in base treatment $\mathrm{B}$, this would suggest the relative importance of the lower bound of the interval. If the relation of magnitudes is the opposite, this would suggest the greater importance of the upper bound of the interval. Regardless of whether the magnitude in treatment A exceeds that in treatment B, or vice versa, both results would indicate use of a segregation mechanism in forming expectations-driven reference points.

Although the design of the direct approach is somewhat more complicated for participants than that of our indirect approach (due to the larger amount of information provided and the greater cognitive effort needed to imagine the situations to be evaluated), we continue to believe that the process of reference point 
formation utilizes an integrated mechanism and that inferences should not be based on salience, recency or frequency. Additionally, although we presented probability intervals, the computation of expected values should not pose a problem for business student participants. Moreover, all referents are easily comparable. We thus hypothesize the following:

Prediction 4 There are no differences in the magnitudes of reference point adaptation between participants in the A treatments and their counterparts in the corresponding B treatments.

\subsection{Results}

We designed the control treatment to test whether there were any significant differences in our manner of conducting the study or in our participant pool compared with Arkes et al. (2008). We hypothesized that there would be no such differences. In the control treatment, participants on average asserted that an upward movement of the stock price to $41.12 €$ would yield the same satisfaction for them as last month's price increase to $36 €$. Given Eq. (1) and a stable shape of the value function, the reference point adaptation is $5.12 €\left(P^{*}-P_{1}=41.12 €-36 €\right)$, and the new reference point is $35.12 €$. Frequencies for specific price intervals are reported in Table $3 \mathrm{~A}$ and $\mathrm{B}$.

We compared our results with those of Arkes et al. (2008). In their study, the mean reported price was $\$ 40.24$, with $18.84 \%$ of participants indicating a price equal to or below $\$ 36,35.5 \%$ indicating a price between $\$ 36$ and $\$ 42,25.36 \%$ indicating a price equal to $\$ 42$ and $45.7 \%$ indicating a price above $\$ 42$. A comparison of the two samples with respect to differences in the location and shape of the distribution, using the Kolmogorov-Smirnov-Test, shows that the two data sets are not significantly different $(\mathrm{Z}=0.907, p=.380)$. Any differences in the experimental treatments should therefore result from differences in expectations and not from differences in our manner of conducting the study or differences in the participant pool.

Both base treatments $\mathrm{A}$ and $\mathrm{B}$ incorporate explicit expectations-ranging either from 30 to $50 €$ or 20 to $60 €$-into the basic scenario. The given expected value of the future stock price of $40 €$ roughly fits the mean reported stock price in the control treatment, where no expectations were explicitly given. The mean reported stock price in the base treatment A (B) is $41.69 €$ (41.57€), which implies an adaptation of $5.69 €(5.57 €)$. A statistical comparison of means between the control treatment and the two different base treatments reveals no significant differences (A: MannWhitney-U $=2,116.50 ; p=.782$; B: Mann-Whitney-U $=2,207.50 ; p=.883$ ). This could indicate that participants' implicit expectations in the control treatment are similar to the explicit expectations provided in the base treatments. ${ }^{5}$

\footnotetext{
${ }^{5}$ As we asked participants to reveal their expectations about the current stock price, we are able to statistically compare this information for both treatments. The mean reported expectations in the control treatment with $39.16 €$ are approximately the same size as those in the base treatment A (B) with $38.54 €$ (39.55€). Statistical comparisons show no significant differences (A: Mann-Whitney- $U=4,161.50$; $p=0.663$; B: Mann-Whitney-U $=1,992.5 ; p=0.324)$.
} 
Table 3 Results of treatments

\begin{tabular}{lllll}
\hline Price & $\begin{array}{l}\text { Control } \\
\text { treatment } \\
\text { frequency }\end{array}$ & $\begin{array}{l}\text { Base treatment A } \\
\text { frequency }\end{array}$ & $\begin{array}{l}\text { Low treatment A } \\
\text { frequency }\end{array}$ & $\begin{array}{l}\text { High treatment A } \\
\text { frequency }\end{array}$ \\
\hline
\end{tabular}

$A$

\begin{tabular}{|c|c|c|c|c|c|}
\hline & 11 & 6 & 10 & & 5 \\
\hline & 15 & 20 & 24 & & 19 \\
\hline & 18 & 25 & 19 & & 13 \\
\hline & 20 & 17 & 11 & & 33 \\
\hline Mean reported price & $41.12 €$ & 41.6 & & & $43.88 €$ \\
\hline Reference point adaptation & $5.12 €$ & 5.69 & $4 .($ & & $7.88 €$ \\
\hline Number of participants & 64 & 68 & 64 & & 70 \\
\hline Price & $\begin{array}{l}\text { Control } \\
\text { frequen }\end{array}$ & ment & $\begin{array}{l}\text { Base treatment B } \\
\text { frequency }\end{array}$ & $\begin{array}{l}\text { Low } \\
\text { treatment B }\end{array}$ & $\begin{array}{l}\text { High treatment B } \\
\text { frequency }\end{array}$ \\
\hline$B$ & & & & & \\
\hline & 11 & & 9 & 13 & 5 \\
\hline & 15 & & 27 & 30 & 15 \\
\hline & 18 & & 13 & 12 & 8 \\
\hline & 20 & & 21 & 13 & 39 \\
\hline Mean reported price & $41.12 €$ & & $41.57 €$ & $39.94 €$ & $43.54 €$ \\
\hline Reference point adaptation & $5.12 €$ & & $5.57 €$ & $3.94 €$ & $7.54 €$ \\
\hline Number of participants & 64 & & 70 & 68 & 67 \\
\hline
\end{tabular}

We examined the role of expectations in reference point formation by implementing low and high treatments. In the low treatment A (B), we provided a price range of $25-45 €(15-55 €)$, with an expected price of $35 €$, and in the high treatment A (B), we provided a price range from 35 to $55 €(25-65 €)$, with an expected price of $45 €$. The ranges were constructed so that each range should include both the recent status quo (36€) and the mean reported price in the base treatment (41.69€). This should enable participants to more easily adhere to these prices, should expectations be of no real importance.

However, if expectations do play a role in the formation of reference points, we should expect low (high) reported mean stock prices compared with the base treatment when expectations are lower (higher). Table $3 \mathrm{~A}$ and $\mathrm{B}$ indicate the distributions and means of participants in the low and the high treatments.

The average answer in the low treatment A (B) was $40.09 €(39.94 €)$, which implies an adaptation of $4.09 €$ (3.94€). The average answer in the high treatment $\mathrm{A}$ (B) was $43.88 €(43.54 €)$, which implies an adaptation of $7.88 €$ (7.54€). Statistical comparison of the means shows significant differences between the base treatment and the low treatment $\mathrm{A}(\mathrm{U}=1,737.00 ; p=.020)$, between the base treatment and the high treatment $\mathrm{A}(\mathrm{U}=1,891.00 ; p=.017)$, between the base treatment and the low treatment $\mathrm{B}(\mathrm{U}=1,628.50 ; p=.001)$ and between the base treatment and the high treatment $\mathrm{B}(\mathrm{U}=1,919.00 ; p=.023)$. 
Furthermore, Table 3A and B show differences in magnitudes of reference point adaptation between low and high treatments. Compared with the base treatment $\mathrm{A}$ (B), information about higher expected outcomes yields an additional adaptation of $2.19 €^{6}(1.97 €)$. In contrast, information about lower expected outcomes provokes a smaller adaptation of only $1.60 €^{7}(1.63)^{8}$. The impact of expectations on reference point formation is therefore stronger for positive information than for negative information. This finding is in line with the results of Arkes et al. (2008) based on changes in the recent status quo (recent stock price). They found that adaptation after gains is greater than after losses.

In summary, we find that expectations tend to influence the adaptation of reference points, corroborating our predictions $3 \mathrm{a}$ and $3 \mathrm{~b}$. Additionally, consistent with Arkes et al. (2008), we find that participants shift reference points upward more strongly if expected values exceed those based on information contained in the recent status quo, and they adapt less strongly if expected values are lower.

To analyze whether participants employed the expected value as a reference point or utilized a segregation mechanism to compute the reference point, we must compare outcomes of treatments with the same expected values, e.g., base treatment A with base treatment $\mathrm{B}$. We find, in accordance with prediction 4 , no statistically significant differences between base treatments $\mathrm{A}$ and $\mathrm{B}(\mathrm{U}=2,204.50 ; p=.446)$, low treatments $\mathrm{A}$ and $\mathrm{B}(\mathrm{U}=2,007.50 ; p=.436)$ or high treatments $\mathrm{A}$ and $\mathrm{B}$ $(\mathrm{U}=2,256.00 ; p=.699)$. This corroborates our prediction that participants use an integrated approach when forming expectation-driven reference points.

Additional statistical evidence is provided by regression analysis and estimations of the effects of expected values and extreme values on reference point formation, using all data. Accordingly, we run the following two regression equations:

$$
\begin{aligned}
& \text { Model } 1: R_{i, t}=\beta_{0}+\beta_{E V} E V_{t}+\beta_{H V} H V_{t}+\varepsilon_{i, t} ; \\
& \text { Model } 2: R_{i, t}=\beta_{0}+\beta_{E V} E V_{t}+\beta_{L V} L V_{t}+\varepsilon_{i, t} .
\end{aligned}
$$

The dependent variable is the reported price (i.e., the reference point) for each participant $i$ and each treatment $t$. The independent variables are the expected values (EV) and either the higher bound (High Value, HV) or the lower bound (Lower Value, LV) of the possibility intervals. As expected, the coefficients point in the same directions as the results of the group comparisons. Relatively high weights$\beta_{\mathrm{EV}}=0.279$ in model 1 and $\beta_{\mathrm{EV}}=0.331$ in model 2 -are given to the expected values $(p=.000)$. In contrast, the effects of the lower bound of the probability interval $\left(\beta_{\mathrm{LV}}=0.046\right.$ in model 1$)$ or the upper bound of the probability interval $\left(\beta_{\mathrm{HV}}=-0.038\right.$ in model 2$)$ are marginal and not significant $\left(p_{\mathrm{LV}}=0.544\right.$; $\left.p_{\mathrm{HV}}=0.544\right)$. Thus, prediction 4 is confirmed.

\footnotetext{
${ }^{6}$ Reference point adaptation high treatment A (7.88€) minus reference point adaptation base treatment A (5.69€).

7 Reference point adaptation base treatment A (5.69€) minus reference point adaptation low treatment A (4.09€).

8 A statistical comparison of the squared differences in reference point adaptation compared with the base treatment for treatments low and high A confirms the differences on a significant level $(\mathrm{U}=1,866.00 ; p=0.046)$. This is not true for the comparison between treatments low and high $\mathrm{B}$ $(\mathrm{U}=2,269.00 ; p=0.943)$.
} 


\subsection{Discussion}

The results of the questionnaire study replicated the results presented in the experimental study, namely, that expectations are important in the formation of reference points. Our findings can therefore be considered further confirmation of the importance of expectations in reference point formation.

It should be noted that our findings are highly reliable. As we adopted an extended version of the direct approach designed by Arkes et al. (2008), we could compare our results with those of the original study. Both the average reference point, as stated by participants in the control treatment, and the finding that the magnitude of adaptation is larger after positive information than after negative information are consistent with the findings of Arkes et al. (2008).

Furthermore, we were able to confirm indications of the integrative mechanism identified in our experimental study. Neither the highest nor the lowest bound of the probability range became dominant in our questionnaire study. Indeed, our results strongly suggest that expected values constitute reference points. Compared with the indirect study, complete ranges of expectations were provided rather than just two potential outcomes of a lottery. Thus, to form a new reference point, participants needed to process many more potential values. Nevertheless, because expected values could easily be calculated by business students, we expected and found that reference points were influenced by expected values.

It is noteworthy that the average reported reference points for all treatments B are lower than those for the corresponding treatments A. Although the differences are not statistically significant, the uniform pattern suggests a possible range effect. The wider range of possible outcomes in treatments $\mathrm{B}$ entails greater risk compared with treatments A. Under the assumption that participants are, in general, risk-averse and that they try to maximize future subjective value, they might adapt their reference points less strongly. ${ }^{9}$ This behavior would increase the probability of finding oneself in the gain region when actual stock prices are disclosed. In our experimental setting, the range effect does not superimpose the integrative mechanism.

Another possible explanation for the higher reported reference points for treatments A could be loss aversion. Under all treatments B, the probability of falling behind the recent status quo (36€) or even the historical status quo (30€) is higher than under treatments A. Imagine a loss-averse participant who faces a higher risk of falling behind his initial investment. As a hedonic utility maximizer, he would indicate a lower price than would participants facing relatively low risk. This is especially evident in comparing high treatments A and B, as under treatment A, there is only a slight risk of falling behind the recent status quo and no risk at all of falling behind the initial status quo.

In conclusion, it should be noted that all indications of an integrative mechanism are valid only under the tight parameters of the experimental setting. It may be that the segregative mechanism becomes more prevalent if participants face, for

\footnotetext{
${ }^{9}$ For a possible range effect, see, for example, Curley and Yates (1985).
} 
example, sequential choices and thus could learn from experience or if expectations are not as comparable and easily calculable as in our setting.

\section{General discussion and conclusion}

Expectations have long been thought to play a role in reference point formation (Kahneman and Tversky 1979; Kahneman et al. 1986). Furthermore, some recent theoretical models are built on the assumption that past expectations are the main determinant of reference points (Köszegi and Rabin 2007, 2008). Therefore, it appears worthwhile to consider the role of expectations empirically.

Research in this field must overcome several obstacles, as reference points are not directly observable. Therefore, assumptions must be made to arrive at testable hypotheses. The indirect approach assumes a stronger risk appetite below than above the reference point. The direct approach assumes that the shape of the utility function remains unchanged when reference points shift during questioning and that participants can hypothetically assess their future utility. Because the two approaches make different assumptions, we examined the role of expectations under each approach.

Several prior studies have considered the role of expectations empirically. Most closely related to our indirect approach is that of Post et al. (2008). However, because their dynamic game show setting is quite complicated, their results are subject to considerable noise. Our direct approach builds on a new method proposed by Arkes et al. (2008), although the latter authors fix expectations in order to focus on the role of the historical and recent status quo.

To the best of our knowledge, there is very little research on the combination process used in reference point formation, given expectations of future outcomes. In brand choice, Winer (1986) finds that people use an integrated mechanism. In contrast, Ordonez et al. (2000) find that participants employ a segregated mechanism when assessing salary satisfaction, given other peoples' wages.

Clearly, there are several limitations to our study. Under both approaches, we must make certain assumptions to derive testable implications. If these assumptions are not correct, our findings would fail to capture reference point formation. In addition, our participants are students who should be familiar with the calculation of expected values. Our conclusions regarding integration are therefore based on situations in which expected values are easy to assess.

As reference point formation and updating remains an open field, certain important future research directions are worth considering. It would be worthwhile to evaluate what happens when expected values are no longer easily comparable. Do people switch to a segregated mechanism, and, if so, which referent receives the largest weight? Baucells et al. (2011) find that the influence of recent information decays sharply once new information is received and that it does not decay further over time. For our indirect study, this would entail a clear-cut new hypothesis. We would expect that the influence of past expectations lessens when additional lotteries or tasks are inserted between the first lottery and the elicitation of risk preferences. This aspect of new information would be interesting to test in the 
future. Other important types of referents, such as aspiration levels, intermediate wealth states or social norms, could assist people in forming reference points. Such referents should be incorporated into future experiments seeking to explain reference point adaptation over time. In addition, what happens if many salient pieces of information could serve as reference points? To which of these referents would an individual compare the outcome? These are just some of the unanswered questions that remain regarding the formation of reference points.

Acknowledgments This research was supported by the Deutsche Forschungsgemeinschaft (DFG) awarded to Frauke von Bieberstein. We gratefully acknowledge support from the Volkswagen Foundation, Grant no. 85487.

\section{Appendix 1: Instructions for the experiment (treatment 1)}

Welcome to this experiment! Please read these instructions carefully. All decisions you make in this experiment are anonymous. At the end of the experiment you will also be paid out anonymously. During the experiment no communication is allowed.

1. Personal information

How old are you?; What is your field of study?; Please indicate your gender.

\section{General information}

We will be playing two lotteries with you where you can win real money.

To do so we have divided all participants into two groups: Group A and Group B.

You are part of: Group A.

\section{Lottery One}

The first lottery has the following payoffs:

Win $4 \mathrm{CHF}$ with $50 \%$ probability/Win $8 \mathrm{CHF}$ with $50 \%$ probability

We will now toss a coin. Your payoff will be calculated in the following way:

"Heads": Group A wins $4 \mathrm{CHF}$, Group B wins $8 \mathrm{CHF} /$

"Tails": Group A wins 8 CHF, Group B wins 4 CHF.

\section{Lottery Two}

The table below shows in each row two alternatives. You can choose in each row between participation in a lottery (Alternative 1) or a safe payment (Alternative 2).

Please fill in the table below as follows: Start with the first row and move down from row to row. In each row, you have to decide between Alternative 1 and 2. Alternative 1 is the same in each row. Only the safe payment in Alternative 2 increases with each row.

After you have made your choices, we will select one of the rows by chance. This row will determine your payment: If you have selected Alternative 1 in this row, we will play the lottery with you. If you have selected Alternative 2 in this row, you will receive the safe payment.

Please mark in each row only one alternative with a cross (all in all 17 crosses): 


\begin{tabular}{|c|c|c|}
\hline Row & Alternative 1 & Alternative 2 \\
\hline 1 & $\begin{array}{l}10 \mathrm{CHF} \text { with probability of } 50 \% \text {, } \\
0 \mathrm{CHF} \text { with probability of } 50 \%\end{array}$ & $0 \mathrm{CHF}$ for sure \\
\hline 2 & $\begin{array}{l}10 \mathrm{CHF} \text { with probability of } 50 \% \text {, } \\
0 \mathrm{CHF} \text { with probability of } 50 \%\end{array}$ & $0.50 \mathrm{CHF}$ for sure \\
\hline 3 & $\begin{array}{l}10 \mathrm{CHF} \text { with probability of } 50 \% \text {, } \\
0 \mathrm{CHF} \text { with probability of } 50 \%\end{array}$ & $1 \mathrm{CHF}$ for sure \\
\hline 4 & $\begin{array}{l}10 \mathrm{CHF} \text { with probability of } 50 \% \text {, } \\
0 \mathrm{CHF} \text { with probability of } 50 \%\end{array}$ & 1.50 $\mathrm{CHF}$ for sure \\
\hline 5 & $\begin{array}{l}10 \mathrm{CHF} \text { with probability of } 50 \% \text {, } \\
0 \mathrm{CHF} \text { with probability of } 50 \%\end{array}$ & $2 \mathrm{CHF}$ for sure \\
\hline 6 & $\begin{array}{l}10 \mathrm{CHF} \text { with probability of } 50 \% \text {, } \\
0 \mathrm{CHF} \text { with probability of } 50 \%\end{array}$ & 2.50 $\mathrm{CHF}$ for sure \\
\hline 7 & $\begin{array}{l}10 \mathrm{CHF} \text { with probability of } 50 \% \text {, } \\
0 \mathrm{CHF} \text { with probability of } 50 \%\end{array}$ & $3 \mathrm{CHF}$ for sure \\
\hline 8 & $\begin{array}{l}10 \mathrm{CHF} \text { with probability of } 50 \% \text {, } \\
0 \mathrm{CHF} \text { with probability of } 50 \%\end{array}$ & 3.50 $\mathrm{CHF}$ for sure \\
\hline 9 & $\begin{array}{l}10 \mathrm{CHF} \text { with probability of } 50 \% \text {, } \\
0 \mathrm{CHF} \text { with probability of } 50 \%\end{array}$ & $4 \mathrm{CHF}$ for sure \\
\hline 10 & $\begin{array}{l}10 \mathrm{CHF} \text { with probability of } 50 \% \text {, } \\
0 \mathrm{CHF} \text { with probability of } 50 \%\end{array}$ & 4.50 $\mathrm{CHF}$ for sure \\
\hline 11 & $\begin{array}{l}10 \mathrm{CHF} \text { with probability of } 50 \% \text {, } \\
0 \mathrm{CHF} \text { with probability of } 50 \%\end{array}$ & 5 CHF for sure \\
\hline 12 & $\begin{array}{l}10 \mathrm{CHF} \text { with probability of } 50 \% \text {, } \\
0 \mathrm{CHF} \text { with probability of } 50 \%\end{array}$ & 5.50 $\mathrm{CHF}$ for sure \\
\hline 13 & $\begin{array}{l}10 \mathrm{CHF} \text { with probability of } 50 \% \text {, } \\
0 \mathrm{CHF} \text { with probability of } 50 \%\end{array}$ & $6 \mathrm{CHF}$ for sure \\
\hline 14 & $\begin{array}{l}10 \mathrm{CHF} \text { with probability of } 50 \% \text {, } \\
0 \mathrm{CHF} \text { with probability of } 50 \%\end{array}$ & 6.50 $\mathrm{CHF}$ for sure \\
\hline 15 & $\begin{array}{l}10 \mathrm{CHF} \text { with probability of } 50 \% \text {, } \\
0 \mathrm{CHF} \text { with probability of } 50 \%\end{array}$ & $7 \mathrm{CHF}$ for sure \\
\hline 16 & $\begin{array}{l}10 \mathrm{CHF} \text { with probability of } 50 \% \text {, } \\
0 \mathrm{CHF} \text { with probability of } 50 \%\end{array}$ & 7.50 CHF for sure \\
\hline 17 & $\begin{array}{l}10 \mathrm{CHF} \text { with probability of } 50 \% \text {, } \\
0 \mathrm{CHF} \text { with probability of } 50 \%\end{array}$ & $8 \mathrm{CHF}$ for sure \\
\hline
\end{tabular}

\section{Appendix 2: Instructions for the questionnaire study}

Thank you for participating in our short questionnaire study!

Please complete the following questionnaire. Take your time and carefully read the questions. There are no right or wrong answers in the second and third part of the questionnaire. We are only interested in your personal assessment. All answers will be made anonymous. 
1. Personal information

How old are you?; What is your field of study?; Please indicate your gender.

2. Personal assessment

Please imagine the following situation:

"Two months ago, you bought a stock for $30 €$ per share. One month ago, you were delighted to learn the stock was trading higher-at $36 €$ per share. [Only in experimental treatments: One month ago you also learned that this month's stock price is expected to range between $\mathrm{x}$ and $\mathrm{y} €$, with each price within this interval being equally likely.]

This month, you decide to check the stock's price again. At what price would the stock need to trade today to make you just as happy with the stock's price this month as you were when you learned the stock had risen from 30 to $36 €$ last month?"

Please indicate the stock price that would make you just as happy here:

\section{Further information}

Please indicate what stock price you had expected when answering the question on the previous page on "the stock price that would make you just as happy". Please indicate the stock price that you had expected here:

\section{References}

Abdellaoui M (2000) Parameter-free elicitation of utility and probability weighting. Manag Sci 46(11):1497-1512

Abdellaoui M, Bleichrodt H, Paraschiv C (2007) Loss aversion under prospect theory: a parameter-free measurement. Manag Sci 53:1659-1674

Abeler J, Falk A, Götte L, Huffman D (2011) Reference points and effort provision. Am Econ Rev 101:470-492

Arkes HR, Hirshleifer D, Jiang D, Lim S (2008) Reference point adaptation: tests in the domain of security trading. Organ Behav Hum Decis Process 105:67-81

Bartol KM, Martin DC (1998) Applicant referent information at hiring interview and subsequent turnover among part-time workers. J Vocat Behav 53:334-352

Baucells M, Weber M, Welfens F (2011) Reference-point formation and updating. Manag Sci 57(3):506-519

Bell DR, Lattin JM (2000) Looking for loss aversion in scanner panel data. The confounding effect of price response heterogeneity. Mark Sci 19(2):185-200

Breiter HC, Aharon I, Kahneman D, Dale A, Shizgal P (2001) Functional imaging of neural responses to expectancy and experience of monetary gains and losses. Neuron 30:619-639

Chen HA, Rao AR (2002) Close encounters of two kinds: false alarm and dashed hopes. Mark Sci 21(2):178-196

Croson R, Sundali J (2005) The gambler's fallacy and the hot hand: empirical data from casinos. J Risk Uncertain 30(3):195-209

Curley SP, Yates JF (1985) The center and range of the probability interval as factors affecting ambiguity preferences. Organ Behav Hum Decis Process 36(2):273-287

De Meza D, Webb DC (2007) Incentive design under loss aversion. J Eur Econ Assoc 5(1):66-92

Diener E, Sandvik E, Pavot W (1990) Happiness is the frequency, not intensity, of positive versus negative affect. In: Strack F, Argyle M, Schwarz N (eds) The social psychology of subjective wellbeing. Pergamon, New York 
Erev I, Barron G (2005) On adaptation, maximization, and reinforcement learning among cognitive strategies. Psychol Rev 112(4):912-931

Fehr-Duda H, De Gennaro M, Schubert R (2006) Gender, financial risk, and probability weights. Theor Decis 60(2-3):283-313

Gilovich T, Vallone R, Tversky A (1985) The hot hand in basketball: on the misperception of random sequences. Cogn Psychol 17(3):295-314

Gneezy U (2005) Updating the reference level: experimental evidence. In: Zwick R, Rapoport A (eds) Experimental business research. Springer, Dordrecht, pp 263-284

Heath C, Larrick RP, Wu G (1999) Goals as reference points. Cogn Psychol 38(1):79-109

Helson H (1964) Adaptation-level theory: an experimental and systematic approach to behavior. Harper and Row, New York

Heyman J, Mellers B, Tishcenko S, Schwartz A (2004) I was pleased a moment ago: how pleasure varies with background and foreground reference points. Motiv Emot 28(1):65-83

Highhouse S, Brooks-Laber ME, Lin L, Spitzmueller C (2003) What makes a salary seem reasonable? Frequency context effects on starting-salary expectations. J Occup Organ Psychol 76(1):69-81

Hoeffler S, Ariely D, West P (2006) Path dependent preferences: the role of early experience and biased search in preference development. Organ Behav Hum Decis Process 101:215-229

Holt CA, Laury SK (2002) Risk aversion and incentive effects. Am Econ Rev 92(5):1644-1655

Kahneman D (1992) Reference points, anchors, norms, and mixed feelings. Organ Behav Hum Decis Process 51:296-312

Kahneman D, Tversky A (1979) Prospect theory: an analysis of decision under risk. Econometrica 47(2):263-291

Kahneman D, Knetsch JL, Thaler R (1986) Fairness as a constraint on profit seeking: entitlements in the market. Am Econ Rev 76:728-741

Kameda T, Davis JA (1990) The function of the reference point in individual and group risk decision making. Organ Behav Hum Decis Process 46(1):55-76

Klein HJ (1991) Further evidence on the relationship between goal setting and expectancy theories. Organ Behav Hum Decis Process 49:230-257

Koop GJ and Johnson JG (2010) The use of multiple reference points in risky decision making. J Behav Decis Mak 25(1):49-62

Köszegi B, Rabin M (2006) A model of reference-dependent preferences. Q J Econ 121(4):1133-1165

Köszegi B, Rabin M (2007) Reference-dependent risk attitudes. Am Econ Rev 97(4):1047-1073

Lin C-H, Huang W-H, Zeelenberg M (2006) Multiple reference points in investor regret. J Econ Psychol 27(6):781-792

March JG (1996) Learning to be risk averse. Psychol Rev 103(2):309-319

Mazumdar T, Raj SP, Sinha I (2005) Reference price research: review and propositions. J Market 69:84-102

Medvec VH, Madey SF, Gilovich T (1995) When less is more: counterfactual thinking and satisfaction among Olympic medalists. J Pers Soc Psychol 69(4):603-610

Mellers B, Schwartz A, Ho K, Ritov I (1997) Elation and disappointment: emotional responses to risky options. Psychol Sci 8(6):423-429

Mellers B, Schwartz A, Ritov I (1999) Emotion-based choice. J Exp Psychol Gen 128(3):332-345

Ordonez LT, Connolly R, Coughlan R (2000) Multiple reference points in satisfaction and fairness assessment. J Behav Decis Mak 13:329-344

Post T, Van den Assem MJ, Baltussen G, Thaler RH (2008) Deal or no deal? Decision making under risk in a large-payoff game show. Am Econ Rev 98(1):38-71

Rabin M, Vayanos D (2010) The gambler's and hot-hand fallacies: theory and applications. Rev Econ Stud 77(2):730-778

Schmidt U, Zank H (2012) A genuine foundation for prospect theory. J Risk Uncertain 45:97-113

Short JC, Palmer TB (2003) Organizational performance referents: an empirical examination of their content and influences. Organ Behav Hum Decis Process 90(2):209-224

Sulivan K, Kida T (1995) The effect of multiple reference points and prior gains and losses on managers' risky decision making. Organ Behav Hum Decis Process 64(1):76-83

Thaler RH, Johnson EJ (1990) Gambling with the house-money and trying to break even: the effect of prior outcomes on risky choice. Manag Sci 36(6):643-660 
Tversky A, Kahneman D (1992) Advances in prospect theory: cumulative representation of uncertainty. J Risk Uncertain 5(4):297-323

Winer RS (1986) A reference price model of brand choice for frequently purchased products. J Consum Res 13(2):250-256 